\title{
Erratum to: Assessing the impacts of and resilience to Tropical Cyclone Bejisa, Reunion Island (Indian Ocean)
}

\author{
V. K. E. Duvat ${ }^{1}$ - A. K. Magnan ${ }^{2}$ - S. Etienne ${ }^{3}$. \\ C. Salmon ${ }^{1} \cdot$ C. Pignon-Mussaud ${ }^{1}$
}

Published online: 1 August 2016

(C) Springer Science+Business Media Dordrecht 2016

\section{Erratum to: Nat Hazards (2016) 83:601-640 DOI 10.1007/s11069-016-2338-5}

We the authors find it important to clarify the source of the pre-storm data on coastal elevation and its implications on the assessment of the morphological impacts of TC Bejisa. We therefore provide below additional information on Sect. 3.2. This addendum does not replace Sect. 3.2 that it completes.

\section{Material, methods and data treatment}

\subsection{Assessment of morphological impacts}

The pre-storm data on coastal elevation was provided by the 2012-issued Litto3D ${ }^{\circledR}$ (precision in elevation: $20 \mathrm{~cm}$ ) which relies on topographic data collected in September 2008. Accordingly, and given the fact that no topographic database was since then published, the elevation data used in this study to characterize the situation before TC Bejisa date from the end of 2008. The interpretation of morphological impacts is though partially biased, but

The online version of the original article can be found under doi:10.1007/s11069-016-2338-5.

V. K. E. Duvat

virginie.duvat@univ-lr.fr

1 UMR LIENSs 7266, University of la Rochelle-CNRS, Bâtiment ILE, 2 rue Olympe de Gouges, 17000 La Rochelle, France

2 Institute for Sustainable Development and International Relations, 41 rue du Four, 75006 Paris, France

3 CNRS, UMR 6554 LETG, EPHE, PSL Research University, 15 Boulevard de la Mer, 35800 Dinard, France 
this bias is considered as relatively limited for two main reasons. First, beach transects conducted by the BRGM over the 2007-2011 period show that the study area has been both resilient to TC Gamède that had caused erosion in 2007 (case study on Saint-Paul Bay) and relatively stable between 2009 and 2011 (case study on Ermitage Beach) (De la Torre et al. 2012). Second, the two main TCs that occurred over the 2012-2013 period, namely TC Dumile (2-4 January 2013) and TC Felleng (31 January-1 February 2013), were category 1 cyclones that, respectively, were tracked 100 and $450 \mathrm{~km}$ offshore of the western coast of the island. Although these cyclones generated waves (Davy 2015), no scientific study reports their impacts on Saint-Paul coastal systems. As a result, we were not able to estimate the possible residual impacts of these cyclones on the beach-dune systems that were then affected by TC Bejisa. However, the existing literature and the interviews that we conducted with coastal residents indicate that TC Bejisa was the most significant driver of morphological change. As a consequence, the transects that we collected after TC Bejisa (named 'Lidar 2012' on figures showing beach profiles) include the residual impacts of these previous cyclones, at least on the coastal sections that were not resilient to these cyclones.

\section{Reference}

Davy C (2015) Analyse du bruit microsismique associé à la houle dans l'océan Indien. PhD thesis, University of La Reunion, 280 p 